\title{
MULTIPLE VANTAGE POINTS OF THE COMMON OPERATIONAL PICTURE: SUPPORTING INTERNATIONAL TEAMWORK
}

\author{
Michael D. McNeese, Mark S. Pfaff, Erik S. Connors, Joaquin F. Obieta, \\ Ivanna S. Terrell, and Marc A. Friedenberg \\ College of Information Sciences and Technology \\ The Pennsylvania State University \\ University Park, PA
}

\begin{abstract}
This paper summarizes multiple perspectives of the common operational picture (COP) in military and civilian crisis management domains viewed from three vantage points: historical, conceptual, and practical. The term COP extends prior research on large group displays to describe a visual representation of tactical, operational, and strategic information intended to generate situation awareness. We present four strata of interest to formulate an innovative conceptual framework of the COP based on user-team needs: structure, representation, processes, and management. This conceptual framework is applied as part of a review of recent and ongoing projects that examines current research gaps in the application of geographic information systems (GIS) to international humanitarian response.
\end{abstract}

\section{INTRODUCTION}

The objective of this paper is to understand and pinpoint multiple perspectives of what has been referred to as the common operational picture (COP). The paper focuses on military and civilian crisis management domains involving multiple levels of teamwork that are often distributed and asynchronous in practice. To engage a broad perspective, this review will view the COP through historical, conceptual, and practical vantage points. These vantage points are not mutually exclusive but lend themselves to different portrayals of the COP as supported by the literature and our own viewpoints of the subject. We review the historical nature of the COP and how the term is presently used for our target areas of interest which are derived from military communications, command, and control $\left(\mathrm{C}^{3}\right)$ and network-centric operations. The perspective of geographic information systems (GIS) research provides a compelling context to explore these points in detail.

\section{BACKGROUND}

\section{History of the COP}

In the last 15 years, a series of events and environmental changes have forced government, military, and civilian sectors to re-evaluate their interrelatedness and ability to respond effectively to crisis situations. Moving from individual operations coordinated by a central entity high in the command ladder to a flatter organizational structure poses many challenges. Further concerns have arisen due to the inclusion of multiple organizations from many nations in large-scale joint efforts such as NATO peacekeeping missions or coordinated counter-terrorist operations. In these scenarios, joint task force commands are expected to cross not only disciplinary but also national and cultural barriers. These are not isolated cases, as administrative policy will make multinational collaboration ever more prevalent (Smith, 1999).

Twenty years ago, we addressed team performance and collaborative support of work within the NORAD command post and other $\mathrm{C}^{3}$ operations (McNeese \& Brown, 1986). One of the major information technologies of value was the large group display (LGD). The LGD functioned as a device that attuned team situation awareness (SA) (Endsley, 1995) to a central position, drawing individual work into collaborative activity. The importance of establishing common ground across disparate roles and responsibilities was revealed while examining the human factors of LGDs in command posts, especially for problems that change in the midst of uncertain situations. The idea of common ground implies that team members are able to share an understanding of a situation. When common ground increases, team performance improves. The current focus on COP can be seen as an extension of LGDs.

COP is a term used to describe a visual representation of tactical, operational, and strategic information to support rapid assimilation and integration by team members. It is used as an information tool in command and control centers to generate situational awareness (Hager, 1997), and can be found at multiple levels of command. Development of a COP takes place from the ground up, but once complete, the knowledge must be redistributed back down the organizational 
hierarchy. COPs are traditionally associated with decision making at the highest levels of command, but that level of SA is only achieved after data from the field are processed within multiple sublevels of command. Future developments of the COP for Global Command and Control Systems (GCCS) will focus on taking the scope of COP a step further by connecting multinational services in coalition forces. International coalitions will compose a larger share of military activities in the future as NATO aims to integrate member nations to cooperatively support war fighting, counter-terrorist, peace-keeping and humanitarian efforts.

\section{Geographic information systems viewpoints}

Although the domain of geographic information systems does not exclusively express a specific definition or position for COP, it is apparent when observing the uses of GIS for tasks such as mapping, scaling, and observing geographical patterns that the suggestion of a COP is thoroughly expressed. With the evolution of groupware and computer-supported cooperative work (CSCW) tools that allow individuals to store and share information for the development of COP (Boland, Tankasi, \& Te'eni, 1994; Karagiannis, Radermacher, Teufel, \& Wynne, 1994; McDermott \& Mulvihill, 1996), we now find that the functions of GIS are not confined within individual organizations or geographical areas (McCarthy, 1994).

The relevance of GIS views persist because so many large-scale military and civilian efforts are highly geo-spatial and incorporate elements of distance, time, rate, speed, identity, and locality, as well as other factors inherent to geographical entities. Many such entities are highly coupled with ecological and contextual perturbations that impact operations at many levels. We are in an age where GIS functions allow and indeed require individuals from varying cultures, groups, and geographic areas to share common tools for reliable measurement of geo-spatial characteristics. Therefore, this circumstance brings into question: How can GIS tools be used and modified to develop accurate COPs among dispersed teams for individuals and organizations who find it necessary to share geographically related information?

\section{SIGNIFICANT FACTORS IN COP DESIGN}

In the early days of LGD research much of the structure, representation, process, and management of the "joint cognitive system" were ad hoc, mechanistic and linear, or ambiguous. This led to potential goal conflicts, workarounds, and decimation of common ground, which could produce the exact opposite of what was intended. To various degrees, past efforts to produce a COP have encountered some of the same mistakes inflated promises based on a technology-centered inclination. To avoid revisiting these failures, it is necessary to first envision a common operational picture conceptually according to user-team needs. The following strata act to formulate an innovative view of the COP (see Figure 1).

\section{Structure}

First, the COP can be thought of as an object of structure, or a type of multi-purpose knowledge repository. The COP exists as a structure to: (1) capture and portray the historical and emergent state of entities, events, and conditions relevant to the situation; and (2) capture and relay the interrelationships so far as they impact plans, decisions, and inter-action. The COP structure can be thought of as the outer shell that determines the composition and arrangement of COP across the problem space. Much of the structure is coupled with sense-making, knowledge management, and information-seeking needs as they unfold in emerging situations wherein data is transformed into information, and information is inducted collectively into knowledge. The structure that enables the COP then is the backbone that constructs and consolidates knowledge in a logical and cohesive manner according to the socio-cognitive and cultural-technological impetus of teams.

\section{Representation}

Representation for the COP is typically bound to artificial intelligence theory that points to given knowledge representation typologies that serve the overall structure. The representation objects can be thought of as the inner shell of the COP. Success results from representations and visualizations that are highly user-centric, rather than just computationally-convenient or designed strictly from a programmer's mindset. This is a critical need area (a research-specific gap) as it appears that most present COPs are strictly defined in technological terms and developed from non-user-centric perspectives, which is not in the best interests of users or teams.

\section{Processes}

Third, given that the COP at one level provides structure and representation, it must also be viewed as object that invites processes, decisions, and actions. If the COP structure is viewed as a set of affordances, then the processes could be identified as "effectivities" that 
users or analysts engage in (inter-action) to accomplish intentions. Because effectivities are always relevant to the available affordances, inter-action is jointly

determined and emergent. Thus, a COP is an object from which collaborative processes are facilitated. In fact, Brewer and McNeese (2004) identify the following interrelationships within military teamwork:

Teamwork often is founded on the idea of a (1) common operational picture (a common ground of a situation as it unfolds with varying constraints), (2) social construction of knowledge (wherein each specialist on the team brings their knowledge together with other specialists to engage in sensemaking and select decision strategies to understand each other, an event, procedure, or embedded objects in the workplace), (3) emergent temporal properties (where either 1 or 2 change across time as more information is enfolded into the process of knowing; p. 522).

\section{Management}

In some situations, the knowledge management (KM) function of a COP may be completed indirectly (i.e., it is programmed in certain degrees into the infrastructure or architecture as software functions). More often than not, however, KM occurs through human intervention where inter-actions among team members result in making sense of a situation, carrying out intentions and plans, storing knowledge externally with other team members, negotiating meaning (sensemaking), monitoring plans/actions, discovering constraints, and acting to adapt to emerging conditions. Without KM, combinatorial explosions within the COP will serve to overwhelm users. KM must jointly utilize the structure, representation, and processes of a COP to reflect and collect a team's intelligence, skills, and abilities as necessary to attack a given challenge problem or target of opportunity.

\section{DISCUSSION}

The necessity of developing COPs in relation to geographical data is important in habitual tracking of weather and earth patterns (King, 2005). However, the importance of COPs peaks in the wake of calamities such as large scale natural disasters (Deschamps, Greenlee, Pultz, \& Saper, 2002) or terrorist acts (Bradt, 2003) that can result in mass human casualties and damage to geo-political structures. In such instances when international assistance in emergency efforts is necessary, individuals from private, public and governmental organizations must develop a COP despite physical and language barriers (Bui, Cho, Sankaran, \& Sovereign, 2000).

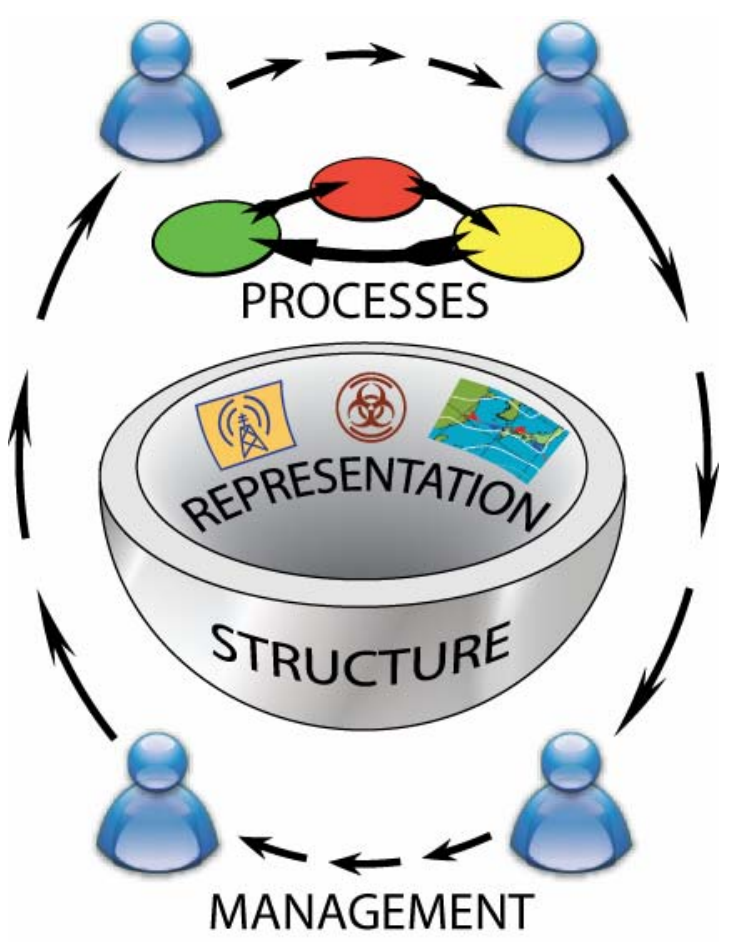

Figure 1: The conceptual model of the COP based on userteam needs: structure, representation, processes, and management.

In the wake of these events, it is necessary to gather and share information for COP development. Such information includes the history, geographical structure, and population/demographic status of the affected country; natural occurrences common to the area; and common health problems in the country (King, 1996). GIS tools can be helpful in predicting the spread of various diseases, assessing the risk of disease in particular areas, and developing health care and sanitation systems (Kaiser, Spiegel, Henderson, \& Gerber, 2003). Additionally, the development of a COP includes ascertaining ground, weather and crop conditions to determine the status of "food security" in a particular region (Pellerin, 2004).

Each of the aforementioned pieces of information is vital in the generation of an accurate COP that will allow individuals to determine appropriate courses of action given certain events that call for the gathering, assessing, and sharing of geographically related information (Benini, Conley, Shdeed, Spurway, \& Yarmoshuk, 2003) among various countries and organizations. The use of GIS for international teamwork provides a context to explicate these four major concepts of the COP:

Structure and representation. the success of the COP depends upon the support of user-centric 
affordances and visualizations designed according to the principles of situated cognition (Greeno \& Moore, 1993). Often this perspective requires fieldwork studies that reveal the "common ground" as it unfolds in a real, naturalistic domain that produces inter-action. A layer of complexity is added to such study as the contents presented by the COP - geographic locations, events (past, present, and future), resources, and other data must address linguistic, cultural, and representational differences between collaborating nations.

Processes. The COP then affords two types of functionality: reflector and collector. The data, signals, signs, and information present and portrayed yield the basic material for team members to disseminate, share, discuss, and finally construct knowledge that can be used directly for operational readiness. Without the means to grasp a common viewpoint of a given situation, it is likely that involved organizations will have difficulty determining who has access to which resources, who will be responsible for which actions, and will also encounter disagreements regarding priority of actions and situations (Bui et al., 2000). This social construction of knowledge process is heavily tied to (1) sense-making and (2) transactive memory (Levine \& Moreland, 2002; Wegner, 1987).

Management. Well-intentioned efforts to share information between organizations via database integration have led to a myriad of problems such as data redundancies and information gaps as well as mapping differences and disagreements (Kamontum, 2005). Furthermore, attempts to develop accurate, geographically-based COPs between organizations from diverse countries can be even more problematic. In order for these organizations to effectively integrate and share data with each other, certain knowledge management requirements must first be met, such as: acceptance of standardized policies; data standards; software for seeking, gathering, sharing, and using information; and training individuals to work with representatives from other agencies to effectively meet data sharing efforts for the generation of well defined COPs (Neches, Yao, Ko, Bugacov, Kumar \& Eleish, 2002; Rajabifard, Mansourian, Zoef, \& Williamson, 2004).

It should also be noted that GIS-driven tools can be integrated with scaled-world simulations to model or provide scenarios for potentially calamitous events, such as earthquakes or terrorist attacks. One such tool, the synthetic task environment NeoCITIES (Jones, McNeese, Connors, Jefferson, \& Hall, 2004; McNeese, Bains, Brewer, Brown, Connors, Jefferson, Jones \& Terrell, 2005) allows individuals to share maps and related geographical information to generate COPs regarding various simulated terrorist or humanitarian crisis scenarios in order to determine appropriate decisive actions. This tool is currently being extended to incorporate a web portal that will allow users to store, share, and access web-based geographic information to enhance COPs related to the scenarios presented within the simulation.

We have taken a broad view of the Common Operational Picture that spans conceptual, historical, and research-specific perspectives in order to frame the COP in terms of what has been, as well as what could be. There is much to be explored and learned from COP failures and successes given the differing forms of implementation in real environments. However, it is clear that most existing COP artifacts are not very usercentric, designed without participation from active teams, rarely consider the ecological or contextual perturbations that require adaptive activities, generally ignore lessons learned from ethnographic data, and are particularly uninformed regarding the current state-ofthe-art research from CSCW and GIS perspectives. The conceptual framework demonstrated here should aid in future COP development.

\section{REFERENCES}

Benini, A. A., Conley, C. E., Shdeed, R., Spurway, K., \& Yarmoshuk, M. (2003). Integration of different data bodies for humanitarian decision support: An example from mine action. Disasters, 27(4), 288304.

Boland, R. J. J., Tankasi, R. V., \& Te'eni, D. (1994). Designing information technology to support distributed cognition. Organization Science, 5(3), 456-475.

Bradt, D. A. (2003). Site management of health issues in the 2001 world trade center disaster. Academic Emergency Medicine, 10(6), 650-660.

Brewer, I. and McNeese, M. (2004). Expanding concept mapping to address spatio-temporal dimensionality. In A. Cañas, D. Novak and F. M. Gonzales (Eds.) Concept Maps: Theory, Methodology, Technology: Proceedings of the First International Conference on Concept Mapping (Pamplona, Spain), 1:101-107.

Bui, T., Cho, S., Sankaran, S., \& Sovereign, M. (2000). A framework for designing a global information network for multinational humanitarian assistance/disaster relief. Information Systems Frontiers, 1(4), 427-442.

Deschamps, A., Greenlee, D., Pultz, T. J., \& Saper, R. (2002). Geospatial data integration for applications in flood prediction and management in the Red River Basin. Geoscience and Remote Sensing Symposium,2002. IGARSS '02. 2002 IEEE International, 6, 33383340.

Endsley, M. R. (1995) Toward a theory of situation awareness in dynamic systems. Human Factors, 37(1), 32-64. 
Greeno, J. G., \& Moore, J. L. (1993). Situativity and symbols: Response to Vera and Simon. Cognitive Science, 17, 49-60.

Hager, R. S. (1997). Current and future efforts to vary the level of detail for the common operational picture. Naval Postgraduate School, Monterrey, California.

Jones, R. E. T., McNeese, M. D., Connors, E. S., Jefferson, T. J., \& Hall, D. L. (2004). A distributed cognition simulation involving homeland security and defense: The development of NeoCITIES. Proceedings of the Human Factors and Ergonomics Society $48^{\text {th }}$ Annual Meeting, (New Orleans, LA), Santa Monica, CA: Human Factors and Ergonomics Society, 2004, 631634.

Kaiser, R., Spiegel, P. B., Henderson, A. K., \& Gerber, M. L. (2003). The application of geographic information systems and global positioning systems in humanitarian emergencies: Lessons learned, programme implications and future research. Disasters, 27(2), 127-140.

Kamontum, S. (2005). Part 1: Using of GIS for Flood Mitigation in Thailand. Retrieved August 18, 2005, from http://www.clas.ufl.edu/users/mbinford/geo5159/revi ew_papers_2005/flooding_siripon.pdf

Karagiannis, D., Radermacher, F. J., Teufel, B., \& Wynne, B. E. (1994). Towards CSCW: Metalevel environments for enhanced group and organization effectiveness. Journal of Organizational Computing and Electronic Commerce, 4(4), 367-392.

King, D. (2005). Humanitarian knowledge management. Proceedings of the Second International ISCRAM Conference, Brussels, Belgium.

Levine J. M., Moreland, R. L. (2004). Collaboration: The social context of theory development. Personality and Social Psychology Review, 8, 164-172.

McCarthy, J. (1994). The state-of-the-art of CSCW: CSCW systems, cooperative work and organization. Journal of Information Technology, 9(2), 73-83.
McDermott, G., \& Mulvihill, C. (1996). Dynamic workflow analysis in a multiuser task context. International Journal of Human-Computer Interaction, 8(4), 433455.

McNeese, M. D., Bains, P., Brewer, I., Brown, C., Connors, E. S., Jefferson, T., Jones, R. E. T., Terrell, I. (2005). The NeoCITIES simulation: Understanding the design and experimental methodology used to develop a team emergency management simulation. Proceedings of the Human Factors and Ergonomics Society $49^{\text {th }}$ Annual Meeting (Orlando, FL), Santa Monica, CA: Human Factors and Ergonomics Society, 2005, 591-594.

McNeese, M. D., \& Brown, C. E. (1986). Large group displays and team performance: An evaluation and projection of guidelines, research, and technologies (AAMRL-TR-86-035). Wright-Patterson Air Force Base, OH: Armstrong Aerospace Medical Laboratory.

Neches, R., Yao, K., Ko, I., Bugacov, A., Kumar, V., \& Eleish, R. (2002). GeoWorlds: Integrating GIS and digital libraries for situation understanding and management. The New Review of Hypermedia and Multimedia, 7(1), 127-152.

Pellerin, C. (2004). Humanitarian Aid a Growing Application for "Digital Diplomacy". Retrieved October 28, 2005, from http://usembassyaustralia.state.gov/hyper/2004/1013/ epf309.htm

Rajabifard, A., Mansourian, A., Zoef, M. J. V., \& Williamson, I. (2004, May 9-12). Developing Spatial Data Infrastructure to Facilitate Disaster Management. Proceedings of GEOMATICS'83 Conference, Tehran, Iran.

Smith, R. A. (1999). The technologically hollow force of the 21st century. Air Force Journal of Logistics, 23(2), 8-12.

Wegner, D. (1987). Transactive memory: a contemporary analysis of the group mind. In B. Mullen and G. Goethals (Eds.), Theories of group behavior (pp. 185-208). New York: Springer-Verlag. 